1 Universidade Federal da Bahia (UFBA), Instituto de Saúde Coletiva (ISC) Salvador (BA), Brasil. vinicio_oliveira@hotmail. com

2 Universidade Federal da Bahia (UFBA), Instituto de Saúde Coletiva (ISC) Salvador (BA), Brasil. catharinamatos@gmail.com

3 Universidade Federal da Bahia (UFBA), Instituto de Saúde Coletiva (ISC) Salvador (BA), Brasil. lilianapsico@gmail.com

4 Universidade Federal da Bahia (UFBA), Escola de Enfermagem - Salvador (BA), Brasil.

ednirassis@hotmail.com

5 Universidade Federal da Bahia (UFBA), Instituto de Saúde Coletiva (ISC) Salvador (BA), Brasil. isabela@ufba.br

\section{Trabalho e educação na saúde: análise da produção científica brasileira entre 2011 e 2014}

\author{
Work and Education in Health: analysis of the Brazilian scientific \\ production between 2011 and 2014
}

Vinício Oliveira da Silva', Catharina Matos Soares², Liliana Santos $\mathbf{3}$, Ednir Assis Souza4, Isabela Cardoso de Matos Pinto 5

RESUMO O estudo aqui relatado teve como objetivo atualizar a análise da produção científica sobre trabalho e educação na saúde no Brasil para o período 2011 a 2014. Trata-se de um estudo de síntese com um total de 757 artigos analisados. A categoria 'Formação-Capacitação' manteve a liderança do número de publicações (51,9\%), seguida de 'Profissionais de Saúde' (42,4\%). Houve redução do percentual de publicações sobre mercado de trabalho, política de recursos humanos e administração de recursos humanos. Os últimos investimentos na formação e capacitação dos trabalhadores podem contribuir para a produção de novos trabalhos baseados no cotidiano dos serviços, sendo necessário avançar no detalhamento da produção científica.

PALAVRAS-CHAVE Saúde coletiva. Força de trabalho. Profissionais de saúde. Formação profissional. Recursos Humanos em Saúde.

ABSTRACT The study here reported aimed to update the analysis of scientific production on work and education in health in Brazil for the period 2011 to 2014. This is a synthesis study that analyzed 757 papers. The category 'Training-Qualification' responded for the majority of publications (51.9\%), followed by 'Health Professionals' category (42.4\%). There has been a reduction in the percentage of publications on labor market, human resources policy and human resources administration. Current investments in training and qualification of workers can contribute to the production of new researches based on everyday services, being necessary to further the scientific production detailing as well.

KEYWORDS Public health. Labor force. Health personnel. Professional training. Health manpower. 


\section{Introdução}

A preocupação com a problemática relacionada à força de trabalho em saúde vem sendo objeto de análise ao longo do processo de implantação do Sistema Único de Saúde (SUS) (PAIM, 1994; SCHRAIBER; PEDUZZI, 1993). Nesse sentido, vem se constituindo a área de pesquisa intitulada 'trabalho e educação na saúde', que envolve olhares e abordagens diversificadas na produção de conhecimento acerca das práticas e das políticas públicas relacionadas à formação de pessoal, distribuição e inserção da força de trabalho em saúde nos sistemas e instituições do setor.

As mudanças decorrentes da descentralização da gestão e da reorganização da atenção à saúde no SUS vêm ocasionando o aumento do contingente de força de trabalho em saúde no âmbito municipal (MACHADO, 2006), especialmente em unidades que compõem a rede de atenção básica, e em novas funções gerenciais, processo que tem estimulado a introdução de mudanças no âmbito da formação profissional na área. Com isso, novas questões foram incorporadas à agenda de pesquisa, definindo contornos adicionais à produção científica da área (PINTO ET AL., 2013).

Estudo realizado por Schraiber e Peduzzi (1993) intitulado 'Tendências e possibilidades da investigação de recursos humanos em saúde no Brasil' mapeou a produção científica da área nas décadas de 1970 e 1980, revelando que dois terços da produção dividiam-se, igualmente, entre estudos classificados na categoria 'Profissionais de Saúde' e os classificados na categoria 'Formação e Capacitação de Recursos Humanos em Saúde'. As autoras ressaltam a relevância do tema e definem certos limites para os recortes teórico-metodológicos utilizados nos estudos.

Posteriormente, no ano 2000, com o workshop 'Mapeamento de projetos de pesquisa e de intervenção sobre recursos humanos em saúde no âmbito nacional', foi realizada uma iniciativa de atualização e aprofundamento da discussão sobre a produção científica dessa área. Tal evento contou com a participação de diversas instituições interessadas e comprometidas com a questão dos Recursos Humanos em Saúde (RHS), que revelou a necessidade de dar prosseguimento ao mapeamento de modo a torná-lo mais completo no sentido de identificar as lacunas existentes tanto no campo das políticas públicas como no da produção científica (PEDUZZI; SCHRAIBER, 2000).

Reconhecendo a importância desses mapeamentos para a construção e o fortalecimento da área e a necessidade de atualização da produção científica, o Grupo de Pesquisa 'Trabalho e Educação na Saúde', vinculado ao Observatório de Análise Política em Saúde, vem envidando esforços para acompanhar e analisar as tendências que se configuram na produção científica dessa área. Nesse sentido, o estudo realizado por Pinto et al. (2013) sobre a produção registrada em periódicos nacionais no período 19902010 revelou a continuidade da concentração da produção científica na categoria Formação e Capacitação, corroborando o estudo realizado nas décadas de 1970 e 1980 por Schraiber e Peduzzi (1993).

Esses estudos revelam lacunas que estimulam o acompanhamento sistemático e a análise permanente da produção científica com o intuito de orientar pesquisas e subsidiar o monitoramento das políticas públicas no setor. Nesse sentido, esta investigação teve como objetivo atualizar a análise da produção científica sobre trabalho e educação na saúde no Brasil no período de 2011 a 2014 e analisar as principais mudanças ocorridas nos últimos quatro anos em comparação à produção das duas décadas anteriores.

\section{Procedimentos metodológicos}

Trata-se de atualização da análise de produção científica, por meio da qual se pretende traçar um comparativo com estudo realizado anteriormente por Pinto et al. (2013) sobre a 
temática. Portanto, para um estudo que se pretende comparativo, utilizou-se como critério o mesmo método, descritores, bases de dados e categorias analíticas utilizados na pesquisa anterior. Realizou-se um estudo de síntese da produção científica a partir de artigos brasileiros publicados sobre a temática 'trabalho e educação na saúde'. Levaram-se em consideração resumos de artigos brasileiros publicados em língua portuguesa entre 2011 a 2014 no Scientific Electronic Library Online (SciELO) e na Literatura Latino-Americana e do Caribe em Ciências da Saúde (Lilacs). Por meio do acesso direto às próprias bases, utilizaram-se os seguintes descritores: educação; trabalho; processo de trabalho; formação; recursos humanos; tecnologias educacionais; força de trabalho; mercado de trabalho, acrescentando-se o termo saúde.

Além da análise descritiva dos artigos publicados entre 2011 a 2014, realizou-se uma análise por quadriênios. Para esta última, considerou-se o período da revisão anterior realizada por Pinto et al. (2013), de 20 anos, mais os quatro anos deste estudo (2011 a 2014), totalizando 24 anos divididos em seis quadriênios, permitindo, assim, uma comparação por períodos. Utilizaram-se, então, os dados dos dois estudos, com cálculo de medidas como proporção e razão a fim de avaliar a tendência das publicações segundo as categorias de análise.

Seguindo os mesmos critérios do estudo anterior, a análise dos trabalhos foi precedida de fase exploratória, onde foram excluídos capítulos de livros, normas técnicas, manuais, teses e dissertações, relatórios técnicos e documentos institucionais. Excluíram-se também aqueles que tratavam de educação popular, educação para o controle social, gestão ampla do conhecimento e informação em saúde. Trabalhos que não continham resumos foram, da mesma forma, descartados. Em alguns casos, quando se utilizavam diferentes descritores ou bases de dados e ocorria a duplicidade de publicações, considerou-se apenas uma vez.
Criou-se um banco de dados em planilhas Excel ${ }^{\circledast}$ para catalogação dos artigos, sintetizando informações como dados de identificação do estudo, ano de publicação, International Standard Serial Number (ISSN) do periódico de publicação, classificação do periódico segundo o Qualis-Capes (Coordenação de Aperfeiçoamento de Pessoal de Nível Superior), tipo de estudo, objetivos, metodologia, resultados e conclusões. O Qualis afere a qualidade dos artigos publicados, a partir da análise da qualidade dos veículos de divulgação, os quais são enquadrados em estratos indicativos da qualidade - A1, o mais elevado; A2; B1; B2; B3; B4; B5; C - com peso zero. Considerando-se a relevância da temática 'trabalho e educação na saúde' para o campo da saúde coletiva, escolheu-se o Qualis-Capes da área para aferir a qualidade da produção científica.

A análise dessas informações implicou a seleção de alguns aspectos: a) o ano de publicação dos artigos, variável que permitiu a análise da evolução temporal do conjunto dos estudos, apresentada sob a forma de gráfico; b) a identificação do periódico implicou a distribuição do conjunto dos trabalhos publicados sob a estratificação para a área da saúde coletiva dos anos 2012, 2013 e 2014 segundo o Qualis-Periódicos - Quando a classificação de um periódico científico não foi encontrada no ano mais recente, foi verificada no ano anterior e assim sucessivamente; e c) a leitura das informações acerca dos objetivos e dos resultados e conclusões apresentados nos artigos conduziu à identificação da área temática onde o estudo se situa, permitindo a classificação do conjunto pelas categorias sugeridas por Schraiber e Peduzzi (1993), e subcategorias sugeridas por Pinto et al. (2013), conforme quadro 1.

Os estudos que não se enquadraram em qualquer das categorias e subcategorias apresentadas foram classificados como 'outros'. Vale ressaltar que foi necessária a revisão das categorias analíticas adotadas no estudo anterior para responder às mudanças 
na constituição da força de trabalho na saúde e na construção de processos educativos em todos os níveis de formação e atuação profissional. Desse modo, foram estabelecidos grupos segundo as categorias temáticas, procedendo-se, em seguida, à análise do tipo de estudo e da metodologia utilizada nos artigos que compunham o total de cada grupo.

Com relação aos tipos de estudo, os trabalhos foram classificados como: ensaios teóricos, cujo objetivo é refletir sobre abordagens e referenciais pertinentes à temática; artigos opinativos sobre o tema; estudos empíricos que utilizam fontes primárias ou secundárias; estudos avaliativos; e relatos de experiência e de intervenções. Quanto à metodologia utilizada na produção e análise das informações, tratou-se de identificar os diversos desenhos de pesquisa indicados. No momento da categorização, foi necessário, para facilitar o aprofundamento da análise, estabelecer subcategorias para os temas mais estudados pelos pesquisadores, os de Formação-Capacitação e Profissionais de Saúde.

Quadro 1. Categorias e subcategorias para análise de estudos sobre trabalho e educação na saúde

\begin{tabular}{|c|c|c|c|c|}
\hline \multicolumn{5}{|c|}{ Categorias } \\
\hline Profissionais de Saúde & Formação e Capacitação de RH em Saúde & $\begin{array}{l}\text { Administração de } \\
\text { RH em Saúde }\end{array}$ & $\begin{array}{l}\text { Mercado de Traba- } \\
\text { Iho em Saúde }\end{array}$ & $\begin{array}{l}\text { Política de RH em } \\
\text { Saúde }\end{array}$ \\
\hline \multicolumn{5}{|c|}{ Conteúdos } \\
\hline Prática Profissional & Processo Educacional ou Práticas Educativas & $\begin{array}{l}\text { Dimensionamento } \\
\text { de Pessoal }\end{array}$ & $\begin{array}{l}\text { Parâmetros quan- } \\
\text { titativos de RH }\end{array}$ & $\begin{array}{l}\text { Configuração e Ten- } \\
\text { dências do Mercado } \\
\text { de Trabalho em Saúde }\end{array}$ \\
\hline $\begin{array}{l}\text { Competências, perfil } \\
\text { e identidade Profis- } \\
\text { sional: Estudos sobre } \\
\text { atribuições, escolha } \\
\text { vocacional, conheci- } \\
\text { mentos necessários e } \\
\text { habilidades para atua- } \\
\text { ção profissional. } \\
\text { Processo de traba- } \\
\text { Iho: Estudos sobre a } \\
\text { prática profissional, } \\
\text { atividades, jornada de } \\
\text { trabalho, análise de } \\
\text { desempenho e produ- } \\
\text { tividade no trabalho, } \\
\text { organização do traba- } \\
\text { Iho e instrumentos de } \\
\text { trabalho. } \\
\text { Saúde do trabalhador } \\
\text { da saúde: Estudos } \\
\text { relacionados à saúde } \\
\text { do trabalhador da saú- } \\
\text { de nos seus diversos } \\
\text { aspectos. }\end{array}$ & $\begin{array}{l}\text { Avaliação: Avaliação de métodos, processos e ins- } \\
\text { trumentos envolvidos na formação e capacitação de } \\
\text { recursos humanos em saúde; avaliação de políticas e } \\
\text { programas de formação; avaliação de cursos. } \\
\text { Estudos sobre currículo: Formulação, implantação, } \\
\text { reforma, integração, estrutura e conteúdo curriculares } \\
\text { em diversas perspectivas de análise. } \\
\text { Processo pedagógico: Estudos sobre aplicação de es- } \\
\text { tratégias e instrumentos didáticos de ensino: processo } \\
\text { ensino-aprendizagem; articulação ensino-serviço; } \\
\text { cenários de práticas, prática docente, metodologias de } \\
\text { ensino. } \\
\text { Análise histórica: Trajetória e histórico de cursos, políti- } \\
\text { cas, programas de formação e instituições de ensino e } \\
\text { história das profissões. } \\
\text { Políticas de formação: Estudos sobre políticas de } \\
\text { formação de recursos humanos em saúde no Brasil: } \\
\text { normatizações, leis, diretrizes e programas de educação } \\
\text { permanente em saúde. } \\
\text { Educação permanente: Estudos sobre atividades de } \\
\text { educação permanente e treinamento em serviço. } \\
\text { Tecnologias da educação: Estudos sobre tecnologias } \\
\text { da informação e comunicação em saúde; Educação a } \\
\text { Distância (EAD). }\end{array}$ & $\begin{array}{l}\text { Critérios para recru- } \\
\text { tamento e seleção } \\
\text { de pessoal } \\
\text { Supervisão e avalia- } \\
\text { ção de RHS } \\
\text { Planos de cargos, } \\
\text { carreiras e salários }\end{array}$ & $\begin{array}{l}\text { Oferta e utilização } \\
\text { de trabalhadores } \\
\text { de saúde }\end{array}$ & $\begin{array}{l}\text { Diretrizes e propostas } \\
\text { políticas definidas por } \\
\text { órgãos oficiais }\end{array}$ \\
\hline
\end{tabular}

Fonte: Adaptado de Pinto et al. (2013); Schraiber e Peduzzi (1993). 


\section{Resultados e discussão}

\section{Evolução temporal da produção cien- tífica sobre trabalho e educação em saúde}

A pesquisa de trabalhos sobre a temática no período compreendido entre 2011 e 2014 resultou no total de 6.829 documentos, sendo selecionados 1.192 resumos de artigos para a análise preliminar. Após a exclusão dos trabalhos que não atendiam aos critérios de inclusão deste estudo e das duplicidades, que totalizaram 435 artigos, analisaram-se 757 resumos.

Ao comparar a produção científica entre 2011 a 2014 com o período correspondente às décadas de 1990 e 2010 analisadas por Pinto et al. (2013), com 532 estudos, verifica-se expressivo crescimento, particularmente, no ano de 2011, quando se produziram $231 \mathrm{pu}-$ blicações. Ao tomar como referência o último ano analisado (2010) no referido estudo, onde se encontraram 90 publicações, o número de artigos em 2011 (231) corresponde a 156,0\% de acréscimo em novos trabalhos.

Nos anos subsequentes, 2012 e 2013, nota-se um declínio, não linear, de, respectivamente, 182 e 191 publicações. Em 2014, com 153 publicações, a redução foi de 33,4\% em relação ao pico verificado em 2011. Ainda assim, a produção manteve-se em níveis mais elevados do que aqueles observados no estudo de Pinto et al. (2013).

Nesse cenário, destaca-se a ação governamental e estímulo às produções relacionadas ao trabalho na saúde, desde 2003, com a criação da Secretaria de Gestão do Trabalho e da Educação na Saúde (SGTES), o que demarca publicamente a necessidade de investimentos nos trabalhadores, já contabilizada pelo próprio Movimento da Reforma Sanitária Brasileira (PAIM, 1994).

As inúmeras ações implantadas pela SGTES ao longo dos últimos anos vêm, certamente, dando maior visibilidade à área, tanto na gestão do trabalho e da educação na saúde como no fomento e desenvolvimento de pesquisas que sugiram soluções para os problemas encontrados, bem como por meio de Editais Nacionais financiados pelo Ministério da Saúde-Decit (Departamento de Ciência e Tecnologia) e pelo Conselho Nacional de Desenvolvimento Científico e Tecnológico (CNPq), além de Editais de Programa Pesquisa para o SUS (PPSUS) em diversos estados, sobretudo a partir de 2005. Dessa forma, observa-se a consolidação da agenda de pesquisa na área que articula os campos do trabalho e da formação em saúde, i.e. educação profissional, superior e permanente.

Considerando os resultados encontrados, cabe registrar como possível limitação deste estudo a adoção, para atender a fins comparativos, da mesma metodologia do estudo anterior (PINTO ET AL., 2013), que havia se valido somente de resumos de artigos publicados no Brasil. Nesse sentido, não se descarta que alguns trabalhos não tenham sido capturados ou que façam parte de outro acervo não contemplado neste estudo, a exemplo das teses e dissertações.

\section{Distribuição dos estudos segundo classificação do periódico onde foi publicado}

A classificação da produção científica foi analisada a partir da estratificação proposta pela Qualis-Periódicos para o campo da saúde coletiva. Do total das publicações, 658 tiveram suas classificações encontradas em 2014; nove, em 2013; 85, em 2012; e em cinco não se encontraram as classificações. No que se refere aos estratos, a maioria das publicações selecionadas é B1 (48\%), seguidas de B2 (32\%), B3 (13\%), B4 (4\%) e A2 (2\%). Além do crescimento do volume, ressaltam-se aspectos qualitativos dessa produção científica, visto que, comparando-se com o estudo anterior, no qual as publicações B1 representaram $19 \%$, seguido de B2 $(16,7 \%)$ e B3 $(44,49)$, houve uma melhoria qualitativa dos estudos, segundo a Qualis-Capes. 
Assim como no estudo anterior, não houve publicações na Al e o número de publicações em revistas A2 permaneceu estável. A produção científica classificada como B1 é encontrada em revistas da área da saúde coletiva, o que contribui para seu maior peso na área, enquanto os estratos B2, B3 e B4 estão publicados, em sua grande maioria, em períodos das áreas de enfermagem, fisioterapia, odontologia, educação física, fonoaudiologia, dentre outras que não fazem parte do campo da saúde.

Acredita-se que a ausência de publicações sobre a temática em periódicos mais qualificados como Al e a baixa produção científica em periódicos $\mathrm{A} 2$ devem-se à própria natureza da temática e ao pequeno número de revistas nacionais na área de classificação adotada, já que se trata de estudo que analisa a produção científica brasileira. Considerando as mudanças no perfil das publicações em relação ao estudo anterior, esta constatação demarca a consolidação de uma área de estudos, bem como abre espaço para a inferência sobre agregação de valores e referências mais consistentes aos estudos apresentados.

\section{Características da produção científi- ca: áreas temáticas e tipo de estudo}

A tabela 1 apresenta a comparação dos artigos selecionados no estudo anterior (PINTO ET AL. 2013), com aqueles encontrados neste estudo, para o período de 2011 a 2014. A fim de facilitar a comparação entre os achados dos dois estudos, os períodos foram divididos em quadriênios. Observou-se que a categoria Formação-Capacitação de RH vem mantendo a liderança na área de trabalho e educação na saúde, com maior proporção de estudos publicados, seguida dos estudos sobre Profissionais de Saúde.

Vale ressaltar que, em relação a esta última categoria, houve redução de 89,6\% em número de publicações no quadriênio 1995 a 1998 quando comparado ao período anterior, ficando atrás das categorias Política de $\mathrm{RH}$ e Mercado de Trabalho. No quadriênio seguinte, a categoria, Profissionais de Saúde, apresenta proporção de estudos 14,3 vezes maior do que a verificada no quadriênio anterior, voltando a ocupar o segundo lugar dentre as categorias. A posição se manteve nos períodos subsequentes, apesar da redução de trabalhos nos oito anos seguintes. No quadriênio 2011 a 2014, essa mesma categoria abarca 42,4\% de todas as publicações, o que faz diminuir a diferença que existia em relação à FormaçãoCapacitação de RH. Enquanto na década de 1990 a proporção de estudos sobre essa categoria chegava a ser três vezes maior do que a de Profissionais de Saúde, no quadriênio 2011 a 2014 a proporção é maior, de 22,4\%.

A Política de RH que, no período de 1995 a 1998 respondeu por aproximadamente 10,0\% das publicações, chega à segunda década de 2000 com a inexpressiva proporção de 0,4\% de publicações. Outras categorias, como Administração de RH e Mercado de Trabalho, cujas proporções variaram entre 1,0 \% e 6,3 \% ou, até mesmo, não foram publicadas em alguns períodos, permanecem com pouca visibilidade no quadriênio 2011 a 2014, visto que, juntas, não chegaram a 5,0\%.

De modo geral, esta análise mostra que a produção científica do último quadriênio apresenta a mesma tendência no que se refere às categorias temáticas, especialmente a predominância das publicações divididas entre Formação-Capacitação e Profissionais de Saúde, corroborando, assim, os achados de Schraiber e Peduzzi (1993) e Pinto et al. (2013), que analisaram a produção científica da área em período anterior. Além disso, ao se comparar a evolução temporal entre estas duas categorias, observa-se que, se por um lado houve uma tímida redução no número de publicações na categoria FormaçãoCapacitação, principalmente quando comparados os dois últimos quadriênios, por outro houve elevado aumento de publicações na categoria Profissionais de Saúde, crescendo de 10,3 no penúltimo quadriênio (2007 a 2010) para 42,4 no ultimo quadriênio (2011 a 2014). 
Tabela 1. Distribuição proporcional, por quadriênios, das publicações sobre trabalho e educação na saúde, segundo a categoria, no período de 1991 a 2014

\begin{tabular}{lrrrrrr}
\hline \multirow{2}{*}{ Categorias } & 1991 a 1994 & 1995 a 1998 & 1999 a 2002 & 2003 a 2006 & 2007 a 2010 & 2011 a 2014 \\
\cline { 2 - 6 } & $\mathrm{N}=24$ & $\mathrm{~N}=48$ & $\mathrm{~N}=70$ & $\mathrm{~N}=101$ & $\mathrm{~N}=281$ & $\mathrm{~N}=757$ \\
\hline Administração de RH & - & 6,3 & 4,3 & - & 5,7 & 3,6 \\
Formação e Capacitação de RH & 62,5 & 75,0 & 62,8 & 71,3 & 74,0 & 51,9 \\
Mercado de Trabalho & 4,2 & 6,3 & - & 1,0 & 3,2 & 1,3 \\
Política de RH & 4,2 & 10,4 & 1,4 & 6,9 & 5,7 & 0,4 \\
Profissionais de Saúde & 20,8 & 2,0 & 28,6 & 16,8 & 10,3 & 42,4 \\
Outros & 8,3 & - & 2,9 & 4,0 & 1,1 & 0,4 \\
\hline Total & 100,0 & 100,0 & 100,0 & 100,0 & 100,0 & 100,0 \\
\hline Fonte: Lilacs: SciElO & & & & & &
\end{tabular}

Fonte: Lilacs; SciELO.

A tabela 2 traz uma síntese dos trabalhos publicados no Brasil no período de 2011 a 2014, baseadas em categorias temáticas e tipos de publicação. A maior parte dos trabalhos publicados está classificada como empíricos (64,3\%), seguida dos ensaios teóricos (17,8\%). Na distribuição das categorias por tipo de estudo, observa-se que em todas predominam os estudos empíricos, onde Profissionais de Saúde (74,8\%) e Administração de RH (74,1\%) apresentam as proporções mais elevadas.

Todos os três estudos sobre Política de RH foram classificados como ensaios teóricos. Em seguida, aparecem os estudos sobre Mercado de Trabalho, que têm 40,0\% de sua produção classificada nessa modalidade. A categoria Formação-Capacitação de $\mathrm{RH}$ foi a que apresentou a maior proporção de estudos classificados como relato de experiência (20,6\%). Com exceção de Formação-Capacitação de RH e da categoria Profissionais de Saúde, com 1,6\% das publicações do tipo relato de experiência, as demais não apresentaram estudos nessa modalidade. Observa-se, ainda, um crescimento na proporção de estudos de revisão da literatura. Enquanto no período de 1990 a 2010 este tipo de estudo representava 2,4\% do total de publicações, entre 2011 a 2014 a proporção elevou-se para 6,5\% (PINTO ET AL., 2013).

Tabela 2. Distribuição proporcional das publicações sobre trabalho e educação na saúde, segundo categoria e tipo de estudo, no período de 2011 a 2014

\begin{tabular}{lrrrrr}
\hline & \multicolumn{5}{c}{ Tipo de estudo } \\
\cline { 2 - 6 } Categorias & N & Estudo Empírico & Ensaio Teórico & $\begin{array}{r}\text { Revisão de } \\
\text { Literatura }\end{array}$ & $\begin{array}{r}\text { Relato de } \\
\text { Experiência }\end{array}$ \\
\hline Administração de RH & 27 & 74,1 & 22,2 & 3,7 & - \\
Formação e Capacitação de RH & 393 & 56,2 & 18,6 & 4,6 & 20,6 \\
Mercado de Trabalho & 10 & 50,0 & 40,0 & 10,0 & - \\
Política de RH & 3 & - & 100,0 & - & 1,6 \\
Profissionais de Saúde & 321 & 74,8 & 14,9 & 3,7 & - \\
Outros & 3 & 33,3 & 33,3 & 33,3 & 11,4 \\
\hline Total & 757 & 64,3 & 17,8 & 6,5 & \\
\hline Fonte: Lilacs: SciElO & & & & &
\end{tabular}




\section{Formação e capacitação dos trabalhadores}

\section{DISTRIBUIC̣ÃO POR SUBCATEGORIA TEMÁTICA}

Os estudos sobre Formação-Capacitação dos trabalhadores da saúde, como visto anteriormente, são os mais numerosos (51,9\%), confirmando os achados dos trabalhos de Schraiber e Peduzzi (1993) e de Pinto et al. (2013), que já evidenciavam o predomínio da categoria. Se por um lado, no período de vinte anos anteriormente analisado por Pinto et al. (2013), a categoria totalizou 379 publicações, por outro, em apenas quatro anos, esse número foi superado, totalizando
393 estudos publicados entre 2011 e 2014, passando de uma média de 18 para 98 publicações por ano.

Dos estudos concentrados na categoria, 157 (39,9\%) abordaram o processo pedagógico, seguido de 63 estudos sobre currículo (16,0\%) e 56 sobre avaliação pedagógica (14,2\%). As demais subcategorias aparecem de forma reduzida, com variações nas proporções entre 3,6\% e 9,9\%. Na estratificação por tipo de estudo, observa-se que a subcategoria Avaliação Pedagógica apresenta a maior proporção de estudos empíricos (92,8\%). Na modalidade ensaio teórico aparecem as subcategorias Análise Histórica, com 42,9\%, e Políticas de Formação, com $33,3 \%$ (tabela 3 ).

Tabela 3. Distribuição proporcional das publicações da categoria Formação e Capacitação de RH, segundo subcategorias e tipos de estudo, Brasil, 2011-2014

\begin{tabular}{|c|c|c|c|c|c|c|}
\hline \multirow{3}{*}{ Subcategorias } & \multicolumn{6}{|c|}{ Tipo de estudo } \\
\hline & \multicolumn{2}{|c|}{$N=393$} & \multirow{2}{*}{$\begin{array}{r}\begin{array}{r}\text { Estudo } \\
\text { Empírico }\end{array} \\
56,2\end{array}$} & \multirow{2}{*}{$\begin{array}{r}\text { Ensaio Teórico } \\
18,6\end{array}$} & \multirow{2}{*}{$\begin{array}{r}\text { Revisão de } \\
\text { Literatura } \\
4,6\end{array}$} & \multirow{2}{*}{$\begin{array}{r}\begin{array}{r}\text { Relato de } \\
\text { Experiência }\end{array} \\
20,6\end{array}$} \\
\hline & $\mathrm{N}$ & $\%$ & & & & \\
\hline Análise Histórica & 14 & 3,6 & 50,0 & 42,9 & - & 7,1 \\
\hline Avaliação & 56 & 14,2 & 92,8 & 28,6 & - & - \\
\hline Educação Permanente & 28 & 7,1 & 60,7 & 17,9 & 3,5 & 17,9 \\
\hline Estudos Sobre Currículo & 63 & 16,0 & 57,2 & 19,0 & 6,3 & 17,5 \\
\hline Políticas de Formação & 15 & 3,8 & 53,3 & 33,3 & - & 13,3 \\
\hline Processo Pedagógico & 157 & 39,9 & 45,2 & 17,8 & 3,2 & 33,8 \\
\hline Tecnologias da Educação & 21 & 5,3 & 33,3 & 23,8 & 4,8 & 38,1 \\
\hline Outros & 39 & 9,9 & 60,0 & 20,5 & 17,9 & 2,6 \\
\hline
\end{tabular}

Fonte: Lilacs; SciELO.

\section{ANÁLISE DE CONTEÚDOS SEGUNDO TIPO DE ESTUDO}

A subcategoria Processo Pedagógico apresenta certa supremacia sobre as demais subcategorias, requerendo, portanto, análise mais aprofundada. A distribuição quantitativa por tipo de estudo demonstra que essa subcategoria é composta por $45,2 \%$ de estudos empíricos, 33,8\% de relatos de experiência, $17,8 \%$ de ensaios teóricos e $3,2 \%$ de revisão da literatura.

Os estudos empíricos incluídos nessa subcategoria centram-se em práticas pedagógicas nos distintos níveis de formação, como graduação (PATRÍcIO ET AL., 2011), pós-graduação (BOTTI; REGO, 2011; ERDMANN ET AL., 2011) e técnico (PEDROSA ET AL., 2011). Abordam, também, 
aspectos relacionados à introdução de metodologias ativas (SILVA; MIGUEL; TEIXEIRA, 2011) ou modalidades de ensino, como Ensino a Distância (EAD) (IAOCHITE ET AL., 2011) ou, ainda, a adesão docente às mudanças curriculares propostas (GARCIA; SILVA, 2011) e a interface dessas propostas de mudanças com as políticas de saúde vigentes (BARROS; CLARO, 2011). Ante aos aspectos destacados, percebe-se a contribuição dos estudos relacionados à formação médica, com 17\% do total de estudos empíricos analisados nessa subcategoria.

Chama à atenção o elevado número de estudos que utiliza a metodologia relato de experiência, o que permite admitir o desenvolvimento de experiências pedagógicas concretas, consideradas, em sua maioria, inovadoras. Nesse sentido, destacam-se as experiências piloto nos diversos cursos da saúde (ABRAHÃO ET AL., 2011; AQUILANTE ET AL., 2011), bem como os resultados obtidos a partir delas (FIGUEIREDO, 2011), apesar de os estudos contemplarem experiências em variados cursos da área; as que estão especificamente relacionadas ao curso médico totalizam $25 \%$ do total de estudos.

Os ensaios teóricos refletem sobre aspectos como as tradições presentes na formação (GOMES ET AL., 2012), as práticas docentes institucionalizadas (MARTIN, 2011), os variados projetos de integração ensino-serviço-pesquisa-comunidade (MESTRINER JUNIOR ET AL., 2011) e aspectos relativos ao currículo (MORENO; SONZOGNO, 2011).

Contudo, do total de 28 estudos teóricos analisados nessa subcategoria, apenas sete (25\%) explicitam o referencial teórico utilizado. Dentre os referenciais teóricos explicitados, destacam-se a sociologia de Goffmann (MORENO; SONZOGNO, 2011), de Pierre Bourdieu (GOMES; REGO, 2013), a antropologia de Geertz (MARTIN, 2011), a pedagogia de Freire (MESTRINER JUNIOR ET AL., 2011; MORETTI-PIRES, 2011; NAMEN; GALAN JUNIOR, 2011) e a proposta estética e pedagógica de Augusto Boal (GOLDSCHMIDT, 2012).

Outros estudos utilizam documentos institucionais nas suas análises históricas, visando a identificar a evolução do ensino na saúde no Brasil (ALMEIDA FILHO ET AL., 2014).

\section{Profissionais de Saúde}

\section{DISTRIBUIC̣ÃO POR SUBCATEGORIA TEMÁTICA}

Assim como no estudo de Pinto et al. (2013), Profissionais de Saúde aparece neste estudo como a segunda categoria onde se concentram as publicações acerca da temática. Observa-se o elevado crescimento do número de publicações dessa categoria entre 2011 e 2014, totalizando 321 (42,4\%), quando comparado ao período das décadas de 1990 e 2010, em que a produção esteve reduzida a um total de 74 publicações (14\%). Esses resultados sugerem significativa contribuição dessa categoria para o crescimento da produção total publicada entre 2011 a 2014.

Observa-se pela tabela 4 que, dos estudos concentrados na categoria Profissionais de Saúde, 46,1\% das publicações abordaram o processo de trabalho, seguidas de estudos sobre saúde do trabalhador da saúde, com 29,3\%, e de estudos sobre competências, perfil e identidade profissional (18,7\%).

Dentre os estudos sobre a temática processo de trabalho, chama à atenção o fato de as abordagens se colarem, hegemonicamente, sob a ótica do sujeito, na tentativa de resgatar sua subjetividade para tratar de temas como comunicação, ética, compromisso ético-politico, humanização, competências, relações, protagonismo, autonomia e transformações no mundo do trabalho.

Essas temáticas revelam, dentre outras questões, que dois aspectos merecem aprofundamento. Primeiro, a dificuldade para aproveitar a fertilidade do referencial marxista em que se encontra inserido o conceito de processo de trabalho. A despeito da importância atribuída pelos estudos à identidade subjetiva no contexto da análise do processo de trabalho, a clara evasão para 
outras linhas teóricas deixa para trás a importante contribuição da produção teórica desenvolvida pela saúde coletiva a partir do final dos anos 1970, com base nos estudos seminais de Cecília Donnangelo e Ricardo Bruno Mendes Gonçalves. O segundo aspecto, consequência do primeiro, é a perda da centralidade do processo de trabalho, como categoria analítica.

Nesse contexto, a diversidade de referenciais teóricos encontrados nos estudos sugere que o desafio de abordar o sujeito e sua subjetividade não tem sido tarefa simples. Dentre os novos aportes conceituais propostos, a Filosofia encontra-se presente em $44 \%$ dessa produção, constituindo-se o pilar de sustentação teórica dessas abordagens. Tal proporção pode ser explicada pelo número expressivo de estudos focados na temática da ética, do compromisso ético-político e da humanização. Por outro lado, surpreende a quase ausência de estudos sob a perspectiva do gênero (3,7\%), visto ser uma dimensão que recorta as relações no trabalho, em especial do trabalho em saúde no Brasil, marcado por crescente contingente feminino.

Também chama à atenção a elevada produção científica sobre saúde do trabalhador da saúde nesses quatro anos quando comparada ao levantamento da produção científica realizado por Pinto et al. (2013), em que essa subcategoria respondeu por apenas $6,9 \% \mathrm{em}$ um período que compreende duas décadas (1990 a 2010).

Tabela 4. Distribuição proporcional das publicações da categoria Profissionais de Saúde, segundo subcategoria e tipo de estudo, Brasil, 2011 - 2014

\begin{tabular}{|c|c|c|c|c|c|c|}
\hline \multirow{3}{*}{ Subcategoria } & & & \multicolumn{4}{|c|}{ Tipo de estudo } \\
\hline & \multicolumn{2}{|c|}{$N=321$} & $\begin{array}{r}\text { Estudo } \\
\text { Empírico }\end{array}$ & $\begin{array}{l}\text { Ensaio } \\
\text { Teórico }\end{array}$ & $\begin{array}{l}\text { Revisão de } \\
\text { Literatura }\end{array}$ & $\begin{array}{r}\text { Relato de } \\
\text { Experiência }\end{array}$ \\
\hline & $\mathrm{N}$ & $\%$ & 74,7 & 14,9 & 8,7 & 1,6 \\
\hline Competências, Perfil e Identidade & 60 & 18,7 & 70,0 & 23,3 & 5,0 & 1,7 \\
\hline Processo de Trabalho & 148 & 46,1 & 70,9 & 18,2 & 9,5 & 1,4 \\
\hline Saúde do Trabalhador da Saúde & 94 & 29,3 & 85,1 & 6,4 & 6,4 & 2,1 \\
\hline Outros & 19 & 5,9 & 68,4 & 5,3 & 26,3 & - \\
\hline
\end{tabular}

Fonte: Lilacs; SciELO.

\section{ANÁLISE DE CONTEÚDO SEGUNDO TIPO DE ESTUDO}

Por se tratar de quase metade da produção científica da categoria Profissionais de Saúde, é importante analisar com maior profundidade a subcategoria Processo de Trabalho em Saúde, que, por sua vez, se distribuiu em 70,9\% de estudos empíricos, $18,2 \%$ de ensaios teóricos, 9,5\% de revisão da literatura e 1,4\% de relatos de experiência.

Os ensaios teóricos incluídos nesta subcategoria abarcaram o debate sobre áreas diversificadas, envolvendo múltiplos referencias tais como materialismo histórico (QUEIROS; LIMA, 2012); ergologia (OLIVEIRA; ALVAREZ; BRITO, 2013); análise institucional, psicodinâmica e agir comunicativo (CARVALHO ET AL., 2012) e filosofia, analisando o saber, o poder e a subjetividade (VIEIRA; SILVEIRA; FRANCO, 2011). Também se abordaram as contribuições da epidemiologia como referencial teórico prático para o trabalho em enfermagem (MEDEIROS ET AL., 2012) e o apoio matricial e equipe de referência como recurso para a organização do trabalho. Vale destacar o trabalho de Vieira e 
Chinelli (2013), que tratam das relações entre trabalho, qualificação e reconhecimento.

Já os estudos empíricos, abordam diversidade de temas, objetos e profissões, com destaque para o fato de a Estratégia Saúde da Família (ESF) envolver distintas profissões de saúde (ALMEIDA; ZANOLLI, 2011; ASSIS ET AL., 2011; BATISTA ET AL., 2011; BERTONCINI; PIRES; SCHERER, 2011; COSTA; FERREIRA ET AL., 2011; MARTINS ET AL., 2012; OLIVEIRA ET AL., 2012; SANT'ANNA ET AL., 2011; TRAD; ROCHA, 2011), bem como o trabalho da enfermagem em diferentes níveis de complexidade $(\mathrm{BAASCH}$; LANER, 2011; MARQUES; MELO, 2011; MASSON; BRITO; ATHAYDE, 2011).

Cabe destacar a presença, dentre esses estudos, de trabalhos que tratam da temática denominada por pesquisadores como gestão do trabalho. Nesse particular, há estudos que abordam a influência das condições de trabalho nas atividades de trabalho (BERTONCINI; PIRES; SCHERER, 2011; LANCMAN ET AL., 2013; MASSON; BRIT; ATHAYDE, 2011; MENDES ET AL., 2013;), motivações no trabalho (MENDES ET AL., 2013), papel da infraestrutura no trabalho humanizado (TRAD; ROCHA, 2011), influência das condições ergonômicas no desenvolvimento do trabalho (COSTA ET AL., 2012), relações de trabalho na ESF no tocante às modalidades de vínculos empregatícios (MARTINS ET AL., 2012) e sofrimento no trabalho (MARQUES; MELO, 2011).

\section{Mercado de Trabalho, Política de RHS e Administração de RHS}

No período deste estudo, 2011 a 2014, houve redução no percentual de publicações sobre mercado de trabalho, política de RHS e administração de RHS quando comparado às duas últimas décadas, 1990 e 2010, analisadas por Pinto et al. (2013). Essa redução foi ainda maior na área de políticas de RHS, reduzindo-se de $5,6 \%$ para $0,4 \%$.

Alguns estudos localizados na categoria Mercado de Trabalho apresentam análises sobre reestruturação produtiva e seu impacto nas relações de trabalho nos serviços públicos de saúde, responsabilizando a fragilidade da regulação do mercado de trabalho no Brasil (MARTINS; MOLINARO, 2013). Pessanha e Artur (2013) discutem sobre as principais mudanças institucionais no mundo do trabalho no Brasil e revelam seus impactos para a organização dos trabalhadores, destacando que os processos de terceirização e jornada de trabalho são temas que têm afetado os trabalhadores da saúde. Por sua vez, Dedecca e Trovão (2013) discutem vantagens e desafios para a força de trabalho no complexo da saúde e abordam sua importância para o mercado brasileiro em um ensaio teórico.

Há ainda estudos que analisam trajetórias, expectativas, percepções e inserção de profissionais de saúde no mercado de trabaIho (BARBOSA ET AL., 2011; JESUS ET AL., 2013; MATOS ET AL., 2014; SILVA ET AL., 2013; TORRES ET AL., 2012).

Os estudos selecionados na categoria Política de RHS são três ensaios teóricos. O primeiro, de Dal Poz et al., (2012), discute a política de formação de Recursos Humanos $(\mathrm{RH})$ na perspectiva da reforma psiquiátrica e destaca os RH como ponto mais frágil da referida reforma. Aciole (2012) apresenta proposta de construção de pacto ético-político entre gestores e trabalhadores do SUS e resgata os movimentos históricos do setor saúde no Brasil em torno dos direitos dos trabalhadores e dos pactos federativos, principalmente no âmbito da gestão. Por sua vez, Dias, Lima e Teixeira (2013) analisam a política nacional de reorientação da formação profissional em saúde.

Os estudos sobre Administração de RHS abordam a avaliação de desempenho dos trabalhadores do setor de saúde pública, planejamento e gestão de RH em saúde, carga de trabalho, capacidade para o trabalho, dimensionamento de pessoal, rotatividade da força de trabalho, taxa de absenteísmo, jornadas de trabalho e condições de trabalho (COELHO ET AL., 2011; FONSECA; VIEIRA, 2011; HILLESHEIN ET AL., 2011; MORAES; IGUTI, 2013; PEREIRA ET AL., 2011; PIERANTONI ET AL., 2011; SANCHO ET AL., 2011; SANCINETTI ET AL., 2011; SILVA; ROTENBERG; FISCHER ET AL., 2011; SILVA JUNIOR ET AL., 2011; QUEIROZ; ALBUQUERQUE; 
MALIK ET AL., 2013; VIANNA ET AL., 2013).

O estudo de Carvalho, Santos e Campos (2013) discute a construção do SUS e o planejamento da força de trabalho em saúde no Brasil a partir de sua trajetória histórica. Nessa perspectiva, outros estudos analisam a gestão da força de trabalho em saúde na atenção básica (JUNQUEIRA ET AL., 2011; MAEDA ET AL., 2011; RIZZOTTO ET AL., 2014; SEIDL ET AL., 2014; TOMAZI; RIZzoTTO, 2013). A regulação do trabalho médico e seus impactos na ESF é analisada por Rodrigues et al., (2013). Outros estudos sobre o profissional médico discutem os fatores críticos para sua fixação da ESF (NEY; RODRIGUES, 2012), necessidade de médicos no interior da Amazônia (SILVEIRA; PINHEIRO, 2014) e como o Brasil tem enfrentado o tema provimento de médicos (CARVALHO; SOUSA, 2013).

$O$ uso de contratos de gestão e incentivos profissionais no setor público de saúde é analisado por Ditterich, Moysés e Moysés (2012). Os Governos Fernando Henrique Cardoso (FHC) e Luís Inácio Lula da Silva (Lula) e a política para a força de trabalho civil do Governo Central Brasileiro são analisados pelo estudo de Costa e Lamarca (2013), que associa a condição da força de trabalho do governo central brasileiro às mudanças na coalizão governamental e alega que a residual participação do Ministério da Saúde (MS) na prestação direta de serviços públicos influenciou a trajetória declinante da força de trabalho federal.

Nessa perspectiva, o estudo de Alberto, Machado e Teixeira (2011) analisa o quadro de trabalhadores federais em saúde no Brasil nos anos 2000, demarcando a importância dos servidores da esfera federal para a conformação institucional do SUS. Fonseca e Vieira (2011) estudaram a conformação e desempenho da força de trabalho no Estado de Minas Gerais na perspectiva de Yves Schwartz, identificando a forte abrangência das estruturas focadas no gerenciamento e rígidas para a organização dos trabalhadores e destacando riscos de cristalização de uma visão funcionalista nesses processos.

\section{Considerações finais}

Este estudo possibilitou o acompanhamento das características da produção científica sobre trabalho e educação na saúde nos últimos anos. Evidenciou-se, por meio das bases de dados Lilacs e SciELO, o elevado crescimento das publicações sobre essa temática no período de quatro anos quando comparadas às décadas anteriores. Foi possível identificar, de fato, quais categorias permanecem com maior número de estudos, quais despontaram com número significativo de trabalhos e quais continuam a apresentar lacunas de conhecimento, o que pode evidenciar desinteresse e falta de investimentos em algumas áreas do trabalho na saúde.

Enquanto categorias como FormaçãoCapacitação de RH e Profissionais de Saúde praticamente dividem a totalidade dos trabalhos produzidos nesses quatro anos, os grupos Administração de RH, Política de RH e Mercado de Trabalho, com poucas contribuições nas décadas anteriores, apresentaram declínio da produção no período estudado. Esses últimos grupos carecem de estudos que possam recomendar soluções para muitos problemas existentes no trabalho em saúde, abarcados por essas esferas esquecidas ou negligenciadas, que ainda se constituem em importantes obstáculos à implantação das políticas para o setor e à consolidação do SUS.

Ao considerar que o êxito das ações de saúde depende da forma como o trabalho está organizado, elementos como número de profissionais, habilidades e competências, distribuição e condições de trabalho revestem-se de grande importância, demandando estudos e trabalhos que não só discutam, mas relatem as experiências bem ou mal sucedidas. Nesse particular, verifica-se modesta contribuição dos relatos de experiência no conjunto de trabalhos analisados, restringindo-se aos estudos sobre formação e capacitação de RH e, em menor número, sobre profissionais de saúde. 
Outros temas também merecem atenção por estarem diretamente relacionados à valorização dos trabalhadores e à correta distribuição de profissionais nos serviços de saúde com base em parâmetros pré-estabelecidos. Toma-se como exemplo, o plano de carreira, cargos e salários e a mitigação da precariedade dos vínculos e dimensionamento da força de trabalho, dentre outros. Apesar da sua importância, ainda há poucos estudos sobre esses assuntos. O mesmo acontece com as políticas, programas e outras iniciativas de promoção da saúde do trabalhador que podem estar sob implantação em algum espaço do território nacional, mas que carecem de divulgação. Esses trabalhos contribuem para identificar as mudanças que vêm ocorrendo no mundo do trabalho em saúde, as dificuldades que vêm sendo enfrentadas em relação a aspectos da gestão do trabalho e as possíveis soluções para os desafios que se verificam no âmbito do SUS.

Não se descarta que alguns trabalhos não tenham sido capturados ou que façam parte de outro acervo não contemplado neste estudo, a exemplo das teses e dissertações. Nos últimos anos, os investimentos na formação e capacitação dos trabalhadores do segmento, por meio de cursos de especialização e mestrados profissionais, podem ter colaborado com a produção de trabalhos baseados no cotidiano dos serviços, o que representaria contribuição importante para a área da saúde. É necessário, portanto, que se prossiga no mapeamento das publicações, se avance na proposta de maior detalhamento dos estudos com a leitura integral dos textos, se vá além das sínteses temáticas e metodológicas e se sumariem as conclusões dos estudos revisados, especialmente daqueles que ainda respondem timidamente pela produção científica.

\section{Colaboradores}

Os autores trabalharam igualmente em todas as etapas de elaboração do manuscrito. 


\section{Referências}

ABRAHÃO, A. L. et al. A pesquisa como dispositivo para o exercício no PET-Saúde UFF/FMS Niterói. Revista Brasileira de Educação Médica, Rio de Janeiro, v. 35, n. 3, p. 435-440, set. 2011. Disponível em: <http:// www.scielo.br/pdf/rbem/v35n3/a19v35n3.pdf >. Acesso em: 2 mar. 2017.

ACIOLE, G. G. Falta um pacto na Saúde: elementos para a construção de um Pacto Ético Político entre gestores e trabalhadores do SUS. Saúde em Debate, Rio de Janeiro, v. 36, n. 95, p. 684-694, 2012. Disponível em: <http://www.scielo.br/scielo.php?pid=S0103$-11042012000400021 \&$ script $=$ sci_abstract\&tlng=pt $>$. Acesso em: 2 mar. 2017.

\section{ALBERTO, L. G.; MACHADO, C. V.; TEIXEIRA, M. O} quadro de trabalhadores federais em saúde no Brasil: uma análise no contexto dos anos 2000. Physis, Rio de Janeiro, v. 21, n. 4, p. 1537-1560, dez. 2011. Disponível em: $<$ http://www.scielo.br/scielo.php?script=sci_artte $x t \& p i d=S 0103-73312011000400019>$. Acesso em: 2 mar. 2017.

\section{ALMEIDA, P. V. B.; ZANOLLI, M. L. O papel} do pediatra no PSF-Paidéia de Campinas (SP). Ciência \&t Saúde Coletiva, Rio de Janeiro, v. 16, sup.1, p. 1479-1488, 2011. Disponível em: < http:// www.scielo.br/scielo.php?script=sci_arttext\&pid =S1413-81232011000700083 >. Acesso em: 2 mar. 2017.

ALMEIDA FILHO, N. et al. Formação médica na UFSB: I. Bacharelado interdisciplinar em saúde no primeiro ciclo. Revista Brasileira de Educação Médica, Rio de Janeiro, v. 38, n. 3, p. 337-348, set. 2014. Disponível em: <http://www.scielo.br/scielo.php?pid=S0100$-55022014000300008 \&$ script $=$ sci_abstract\&tlng $=p t>$. Acesso em: 2 mar. 2017.

AQUILANTE, A. G. et al., Situações-problema simuladas: uma análise do processo de área de saúde. Ciência Et Saúde Coletiva, Rio de Janeiro, v. 16, supl. 1, p. 16111619, 2011.

ASSIS, W. D. et al. Processo de trabalho da enfermeira que atua em puericultura nas unidades de saúde da família. Revista Brasileira de Enfermagem, Brasília, DF, v. 64, n. 1, p. 38-46, fev. 2011. Disponível em: <http://www.scielo.br/scielo.php?pid=S0034$-71672011000100006 \&$ script $=$ sci_abstract $\&$ tlng $=$ pt $>$. Acesso em: 2 mar. 2017.

BAASCH, D.; LANER, A. S. Os significados do trabalho em unidades de terapia intensiva de dois hospitais brasileiros. Ciência \&t Saúde Coletiva, Rio de Janeiro, v. 16, supl. 1, p. 1097-1105, 2011. Disponível em: <http://www.scielo.br/scielo.php?pid=S1413$-81232011000700041 \&$ script=sci_abstract\&tlng $=$ pt $>$. Acesso em: 2 mar. 2017

BARBOSA, T. L. A. et al. Expectativas e percepções dos estudantes do curso técnico em enfermagem com relação ao mercado de trabalho. Texto Contexto Enfermagem, Florianópolis, v. 20, p. 45-51, 2011. Disponível em: <http://www.index-f.com/ textocontexto/2011pdf/20s-045.pdf $>$. Acesso em: 2 mar. 2017.

BARROS, S.; CLARO, H. G. Processo ensino aprendizagem em saúde mental: o olhar do aluno sobre reabilitação psicossocial e cidadania. Revista da Escola de Enfermagem da USP, São Paulo, v. 45, n. 3, p. 700-707, jun. 2011. Disponível em: <http:// www.scielo.br/scielo.php?script=sci_arttext\&pid =S0080-62342011000300022>. Acesso em: 2 mar. 2017.

BATISTA, C. B. et al. Violência no trabalho em saúde: análise em unidades básicas de saúde de Belo Horizonte, Minas Gerais. Trabalho, Educação e Saúde, Rio de Janeiro, v. 9, n. 2, p. 295-317, out. 2011. Disponível em: <http://www.scielo.br/scielo.php?pid=S1981$-77462011000200008 \&$ script $=$ sci_abstract $>$. Acesso em: 2 mar. 2017

BERTONCINI, J. H.; PIRES, D. E. P.; SCHERER, M. D. A. Condições de trabalho e renormalizações nas atividades das enfermeiras na saúde da família. Trabalho, Educação e Saúde, Rio de Janeiro, v. 9, supl. 1, p. 157-173, 2011. Disponível em: <http:// www.scielo.br/scielo.php?script=sci_arttext\&pid $=$ =S1981-77462011000400008>. Acesso em: 2 mar. 2017. 
BOTTI, S. H. O.; REGO, S. T. A. Docente-clínico: o complexo papel do preceptor na residência médica. Physis, Rio de Janeiro, v. 21, n. 1, p. 65-85, 2011. Disponível em: <http://www.scielo.br/scielo.php?pid=S0103$-73312011000100005 \&$ script $=$ sci_abstract $\&$ tlng $=$ pt $>$. Acesso em: 2 mar. 2017

CARVALHO, B. G. et al. Trabalho e intersubjetividade: reflexão teórica sobre sua dialética no campo da saúde e enfermagem. Revista Latino-Americana de Enfermagem, Ribeirão Preto, v. 20, n. 1, p. 19-26, fev. 2012. Disponível em: <http://www.scielo.br/pdf/rlae/ v20n1/pt_04.pdf>. Acesso em: 2 mar. 2017.

CARVALHO, M.; SANTOS, N. R.; CAMPOS, G. W. S A construção do SUS e o planejamento da força de trabalho em saúde no Brasil: breve trajetória histórica. Saúde em debate, Rio de Janeiro, v. 37, n. 98, p. 372-387, set. 2013. Disponível em: <http://www.redalyc.org/ pdf/4063/406341757002.pdf>. Acesso em: 2 mar. 2017.

CARVALHO, M. S.; SOUSA, M.F. Como o Brasil tem enfrentado o tema provimento de médicos. Interface, Botucatu, v. 17, n. 47, p. 913-926, dez. 2013. Disponível em: <http://www.scielo.br/scielo.php?script=sci abstract\&pid=S1414-32832013000400012\&lng=pt\&nrm =iso\&tlng=pt>. Acesso em: 2 mar. 2017.

COELHO, F. U. A. et al. Carga de trabalho de enfermagem em unidade de terapia intensiva de cardiologia e fatores clínicos associados. Texto Contexto Enfermagem, Florianópolis, v. 20, n. 4, p. 735-741, dez. 2011. Disponível em: <http://www.index-f.com/ textocontexto/2011pdf/20-735.pdf>. Acesso em: 2 mar. 2017.

COSTA, A. O. et al. A participação do auxiliar em saúde bucal na equipe de saúde e o ambiente odontológico. Revista de Odontologia da UNESP, Araraquara, v. 41, n. 6, p. 371-376, 2012. Disponível em: <http://www.scielo. $\mathrm{br} / \mathrm{pdf} /$ rounesp/v4ln6/a01v4ln6.pdf $>$. Acesso em: 2 mar. 2017.

COSTA, E. M.; FERREIRA, D. L. A. Percepções e motivações de agentes comunitários de saúde sobre o processo de trabalho em Teresina, Piauí. Trabalho, Educação e Saúde, Rio de Janeiro, v. 9, n. 3, p. 461-478, nov. 2011. Disponível em: <http://www.scielo.br/ scielo.php?pid=S1981-77462011000300007\&script=sci abstract\&tlng=pt>. Acesso em: 2 mar. 2017.

COSTA, N. R.; LAMARCA, I. Os Governos FHC e Lula e a política para a força de trabalho civil do Governo Central Brasileiro. Ciência \& Saúde Coletiva, Rio de Janeiro, v. 18, n. 6, p. 1601-1611, jun. 2013. Disponível em: <http://www.scielo.br/scielo.php?pid=S1413$-81232013000600012 \&$ script $=$ sci_abstract $\&$ tlng $=p t>$. Acesso em: 2 mar. 2017.

DAL POZ, M. R.; LIMA, J. C. S.; PERAZZI, S. Força de trabalho em saúde mental no Brasil: os desafios da reforma psiquiátrica. Physis, Rio de Janeiro, v. 22, n. 2, p. 621-639, jun. 2012. Disponível em: <http://www.scielo.br/scielo.php?pid=S0103$-73312012000200012 \&$ script $=$ sci_abstract\&tlng $=$ pt $>$. Acesso em: 2 mar. 2017.

DEDECCA, C. S.; TROVÃO, C. J. B. M. A força de trabalho no complexo da saúde: vantagens e desafios. Ciência Ét Saúde Coletiva, Rio de Janeiro, v. 18, n. 6, p. 1555-1567, jun. 2013. Disponível em: <http://www.scielo.br/pdf/csc/v18n6/08.pdf>. Acesso em: 2 mar. 2017

DIAS, H. S.; LIMA, L. D.; TEIXEIRA, M. A trajetória da política nacional de reorientação da formação profissional em saúde no SUS. Ciência \& Saúde Coletiva, Rio de Janeiro, v. 18, n. 6, p. 1613-1624, jun. 2013. Disponível em: <http://www.scielosp.org/pdf/csc/v18n6/13.pdf>. Acesso em: 2 mar. 2017.

DITTERICH, R. G.; MOYSÉS, S. T.; MOYSÉS, S. J. O uso de contratos de gestão e incentivos profissionais no setor público de saúde. Cadernos de Saúde Pública, Rio de Janeiro, v. 28, n. 4, p. 615-625, abr. 2012. Disponível em: <http://www.scielo.br/scielo.php?script=sci arttext\&pid=S0102-311X2012000400002 > . Acesso em: 2 mar. 2017

ERDMANN, A. L. et al. Vislumbrando a iniciação científica a partir das orientadoras de bolsistas da Enfermagem. Revista Brasileira de Enfermagem, Brasília, DF, v. 64, n. 2, p. 261-267, abr. 2011. Disponível em: <http://www.scielo.br/pdf/reben/v64n2/ a07v64n2.pdf>. Acesso em: 2 mar. 2017. 
FIGUEIREDO, A. M. Perfil acadêmico dos professores de bioética nos cursos de pós-graduação no Brasil. Revista Brasileira de Educação Médica, Rio de Janeiro, v. 35, n. 2, p. 163-170, jun. 2011. Disponível em: <http:// www.scielo.br/scielo.php?script=sci_arttext\&pid =S0100-55022011000200004>. Acesso em: 2 mar. 2017.

FONSECA, J. C. F.; VIEIRA, C. E. C. Análise pluridisciplinar das situações de trabalho: para além da avaliação de desempenho dos trabalhadores do setor de saúde pública no estado de Minas Gerais. Saúde e Sociedade, São Paulo, v. 20, n. 2, p. 390-397, jun. 2011. Disponível em: <http://www.scielo.br/scielo.php?pid=S0104$-12902011000200011 \&$ script $=$ sci_abstract $\&$ tlng $=$ pt $>$. Acesso em: 2 mar. 2017.

GARCIA, M. A. A.; SILVA, A. L. B. Um perfil do docente de medicina e sua participação na reestruturação curricular. Revista Brasileira de Educação Médica, Rio de Janeiro, v. 35, n. 1, p. 58-68, mar. 2011. Disponível em: <http://www.scielo.br/pdf/rbem/v35nl/a09v35nl. pdf>. Acesso em: 2 mar. 2017.

GOLDSCHMIDT, I. L. O teatro de Augusto Boal e a educação profissional em saúde. Trabalho, Educação e Saúde, Rio de Janeiro, v. 10, n. 1, p. 61-69, 2012. Disponível em: <http://www.scielo.br/scielo. php?pid=S1981-77462012000100004\&script=sci abstract\&tlng=pt>. Acesso em: 2 mar. 2017.

GOMES, A. P.; REGO, S. Pierre Bourdieu e formação médica. Revista Brasileira de Educação Médica, Rio de Janeiro, v. 37, n. 2, p. 260-265, jun. 2013. Disponível em: <http://www.scielo.br/scielo.php?pid=S0100$-55022013000200014 \&$ script $=$ sci_abstract\&tlng $=p t>$. Acesso em: 2 mar. 2017.

GOMES, A. P. et al. Atenção primária à saúde e formação médica: entre episteme e práxis. Revista Brasileira de Educação Médica, Rio de Janeiro, v. 36, n. 4, p. 541549, dez. 2012. Disponível em: <http://www.scielo.br/ pdf/rbem/v36n4/14.pdf>. Acesso em: 2 mar. 2017.

HILLESHEIN, E. F. et al. Capacidade para o trabalho de enfermeiros de um hospital universitário. Revista Gaúcha de Enfermagem, Porto Alegre, v. 32, n. 3, p. 509-515. set. 2011. Disponível em: <http://seer.ufrgs.br/
RevistaGauchadeEnfermagem/article/view/18609>.

Acesso em: 2 mar. 2017.

IAOCHITE, R. T. et al. Autoeficácia docente, satisfação e disposição para continuar na docência por professores de educação física. Revista Brasileira de Ciências do Esporte, Curitiba, v. 33, n. 4, p. 825-839, dez. 2011. Disponível em: <http://www.scielo.br/pdf/rbce/ v33n4/a03v33n4.pdf>. Acesso em: 2 mar. 2017.

JESUS, B. H. et al. Inserção no mercado de trabalho: trajetória de egressos de um curso de graduação em enfermagem. Escola Anna Nery, Rio de Janeiro, v. 17, n. 2, p. 336-345, jun. 2013. Disponível em: <http://www.scielo.br/scielo.php?pid=S1414$-81452013000200019 \&$ script $=$ sci_abstract\&tlng $=p t>$. Acesso em: 2 mar. 2017.

JUNQUEIRA, V. et al. O Pacto pela Saúde e a gestão da força de trabalho na Atenção Básica do SUS: um retrato da situação de alguns municípios no Estado de São Paulo. Physis, Rio de Janeiro, v. 21, n. 2, p. 675-693, 2011. Disponível em: $<$ http://repositorio.unifesp.br/handle/11600/6185>. Acesso em: 2 mar. 2017.

LANCMAN, S. et al. Estudo do trabalho e do trabalhar no Núcleo de Apoio à Saúde da Família. Revista de Saúde Pública, São Paulo, v. 47, n. 5, p. 968-975, out. 2013. Disponível em: <http://www.scielo.br/pdf/rsp/ v47n5/0034-8910-rsp-47-05-0968.pdf>. Acesso em: 2 mar. 2017.

MACHADO, M. H. Trabalhadores da saúde e sua trajetória na Reforma Sanitária. In: BRASIL. Ministério da Saúde. Cadernos RH Saúde. Brasília, DF: Ministério da Saúde, 2006. p. 12-25.

MAEDA, S. T. et al. Recursos humanos na atenção básica: investimento e força propulsora de produção. Revista da Escola de Enfermagem da USP, São Paulo, v. 45, n. 2, p. 1651-1655, dez. 2011. Disponível em: <http:// www.scielo.br/scielo.php?script=sci_arttext\&pid =S0080-62342011000800002 >. Acesso em: 2 mar. 2017.

MARQUES, P. A.; MELO, E.C.P. O processo de trabalho em uma Unidade de Terapia Intensiva Neonatal. Revista da Escola de Enfermagem da USP, São Paulo, v. 
45, n. 2, p. 374-380, abr. 2011. Disponível em: <http:// www.scielo.br/pdf/reeusp/v45n2/v45n2a10>. Acesso em: 2 mar. 2017.

MARTIN, D. Refletindo a formação interdisciplinar na pós-graduação. Saúde e Sociedade, São Paulo, v. 20, n. 1, p. 57-65, jan./mar. 2011. Disponível em: < https://www. revistas.usp.br/sausoc/article/view/29770>. Acesso em: 2 mar. 2017

MARTINS, A. R. et al. Relações interpessoais, equipe de trabalho e seus reflexos na atenção básica. Revista Brasileira de Educação Médica, Rio de Janeiro, v. 36, n. 1, p. 6-12, mar. 2012. Disponível em: <http://www.scielo. $\mathrm{br} / \mathrm{pdf} / \mathrm{rbem} / \mathrm{v} 36 \mathrm{n} 1 \mathrm{~s} 2 / \mathrm{a} 02 \mathrm{v} 36 \mathrm{n} 1 \mathrm{~s} 2$.pdf $>$. Acesso em: 2 mar. 2017.

MARTINS, M. C.; MOLINARO, A. Reestruturação produtiva e seu impacto nas relações de trabalho nos serviços públicos de saúde no Brasil. Ciência \& Saúde Coletiva, Rio de Janeiro, v. 18, n. 6, p. 1667-1676, jun. 2013. Disponível em: <http://www.scielo.br/pdf/csc/ v18n6/18.pdf>. Acesso em: 2 mar. 2017.

MASSON, L. P.; BRITO, J.; THAYDE, M. Dimensão relacional da atividade de cuidado e condições de trabalho de auxiliares de enfermagem em uma unidade neonatal. Physis, Rio de Janeiro, v. 21, n. 3, p. 879-898, 2011. Disponível em: <http://www.scielo.br/scielo. php?pid=S0103-73312011000300007\&script $=$ sci abstract\&tlng=pt>. Acesso em: 2 mar. 2017.

MATOS, F.V. et al. Egressos da residência de medicina de família e comunidade em Minas Gerais. Revista Brasileira de Educação Médica, Rio de Janeiro, v. 38, n. 2, p. 198-204, jun. 2014. Disponível em: <http://www. scielo.br/pdf/rbem/v38n2/a06v38n2.pdf>. Acesso em: 2 mar. 2017.

MEDEIROS, A. R. P. et al. A epidemiologia como referencial teórico-metodológico no processo de trabalho do enfermeiro. Revista da Escola de Enfermagem da USP, São Paulo, v. 46, n. 6, p. 1519-1523, dez. 2012. Disponível em: <http:// www.scielo.br/scielo.php?script=sci_arttext\&pid $=$ S0080-62342012000600032>. Acesso em: 2 mar. 2017.
MENDES, A. C. G. et al. Condições e motivações para o trabalho de enfermeiros e médicos em serviços de emergência de alta complexidade. Revista Brasileira de Enfermagem, Brasília, DF, v. 66, n. 2, p. 161-166, abr. 2013. Disponível em: <http:// www.scielo.br/scielo.php?script=sci_arttext\&pid =S0034-71672013000200002 >. Acesso em: 2 mar. 2017.

MESTRINER JÚNIOR, W. et al. O desenvolvimento de competências em atenção básica à saúde: a experiência no projeto Huka-Katu. Ciência $\mathcal{E}$ Saúde Coletiva, Rio de Janeiro, v. 16, p. 903-912, 2011. Disponível em: <http://www.scielo.br/scielo.php?pid=S1413 $-81232011000700022 \&$ script $=$ sci_abstract $\&$ tlng $=$ pt $>$. Acesso em: 2 mar. 2017.

MORAES, P. N.; IGUTI, A. M. Avaliação do desempenho do trabalhador como forma peculiar de prescrição do trabalho: uma análise do PMAQAB. Saúde em Debate, Rio de Janeiro, v. 37, n. 98, p. 416-426, set. 2013. Disponível em: <http:// www.scielo.br/scielo.php?script=sci_arttext\&pid =S0103-11042013000300005>. Acesso em: 2 mar. 2017

MORENO, L. R.; SONZOGNO, M. C. Formação pedagógica na pós-graduação em saúde no ambiente Moodle: um compromisso social. Pro-Posições, Campinas, v. 22, n. 3, p. 149-164, dez. 2011. Disponível em: <http://www. scielo.br/pdf/pp/v22n3/11.pdf $>$. Acesso em: 2 mar. 2017.

MORETTI-PIRES, R. O. O pensamento freireano como superação de desafios do ensino para o SUS. Revista Brasileira de Educação Médica, Rio de Janeiro, v. 36, n. 2, p. 255-263, jun. 2012. Disponível em: <http://www. scielo.br/pdf/rbem/v36n2/15.pdf>. Acesso em: 2 mar. 2017.

NAMEN, F. M.; GALAN, J. J. Reflexões sobre a educação de profissionais da área de saúde. Ciência $\mathcal{E}$ Saúde Coletiva, Rio de Janeiro, v. 16, supl.1, p.1611-1619, 2011. Disponível em: <http://www.scielo.br/scielo. php?pid=S1413-81232011000700097\&script=sci_ abstract\&tlng=pt>. Acesso em: 2 mar. 2017.

NEY, M. S.; RODRIGUES, P. H. A. Fatores críticos para a fixação do médico na Estratégia Saúde da 
Família. Physis, Rio de Janeiro, v. 22, n. 4, p. 1293-1311, 2012. Disponível em: <http://www.scielo.br/scielo. php?pid=S0103-73312012000400003\&script=sci abstract\&tlng=pt $>$. Acesso em: 2 mar. 2017.

OLIVEIRA, A. K. S. et al. Experiências alternativas resgatando saberes para os processos de trabalho em saúde. Revista da Escola de Enfermagem da USP, São Paulo, v. 46, n. 4, p. 953-959, ago. 2012. Disponível em: $<$ http://www.scielo.br/scielo.php?script=sci_arttext\& pid=S0080-62342012000400024>. Acesso em: 2 mar. 2017.

OLIVEIRA, S.; ALVAREZ, D.; BRITO, J. A dimensão gestionária do trabalho: aspectos da atividade de cuidado. Ciência \&t Saúde Coletiva, Rio de Janeiro, jun. 2013 v. 18, n. 6, p. 1581-1589. Disponível em: <http://www. scielosp.org/pdf/csc/v18n6/10.pdf>. Acesso em: 2 mar. 2017.

PAIM, J. S. Recursos Humanos em Saúde no Brasil: problemas crônicos e desafios agudos. São Paulo: USP, 1994.

PATRÍCIO, Z. M. et al. Sistematização de estratégias de ensinar-aprender pesquisa na graduação. Interface, Botucatu, v. 15, n. 39, p. 1159-1172, dez. 2011. Disponível em: <http://www.scielo.br/pdf/icse/2011nahead/ aop2811>. Acesso em: 2 mar. 2017.

PEDROSA, I. L. et al. Uso de metodologias ativas na formação técnica do agente comunitário de saúde. Trabalho, Educação e Saúde, Rio de Janeiro, v. 9, n. 2, p. 319-332, out. 2011. Disponível em: <http://www.scielo.br/scielo.php?pid=S1981$-77462011000200009 \&$ script=sci_abstract $\&$ tlng=pt $>$. Acesso em: 2 mar. 2017.

PEDUZZI, M.; SCHRAIBER, L. B. Workshop: mapeamento de projetos de pesquisa e de intervenção sobre recursos humanos em saúde, no âmbito nacional. Interface, Botucatu, v. 4, n. 7, p. 149-152, 2000. Disponível em: <http://www. scielo.br/scielo.php?script=sci_arttext\&pid =S1414-32832000000200019>. Acesso em: 2 mar. 2017.

PEREIRA, I. M. et al. Dimensionamento informatizado de profissionais de enfermagem: avaliação de um software. Revista da Escola de Enfermagem da USP, São Paulo, v. 45, p.1600-1605, dez. 2011. Disponível em: <http://www.scielo.br/pdf/reeusp/v43nspe2/ a29v43s2.pdf $>$. Acesso em: 2 mar. 2017.

PESSANHA, E. G. F.; ARTUR, K. Direitos trabalhistas e organização dos trabalhadores num contexto de mudanças no mundo do trabalho: efeitos sobre os trabalhadores da saúde. Ciência \&t Saúde Coletiva, Rio de Janeiro v. 18, n. 6, p. 1569-1580, jun. 2013. Disponível em: <http://www.scielosp.org/pdf/csc/v18n6/09.pdf>. Acesso em: 2 mar. 2017.

PIERANTONI, C. R. et al. Avaliação de desempenho: discutindo a tecnologia para o planejamento e gestão de recursos humanos em saúde. Revista da Escola de Enfermagem da USP, São Paulo, v. 45, p. 1627-1631, dez. 2011. Disponível em: <http://www.scielo.br/scielo. php?pid=S0080-62342011000700014\&script $=$ sci abstract\&tlng=pt $>$. Acesso em: 2 mar. 2017.

PINTO, I. C. M. et al. Trabalho e educação em saúde no Brasil: tendências da produção científica entre 19902010. Ciência \&t Saúde Coletiva, Rio de Janeiro, v. 18, p. 1525-1534, 2013. Disponível em: <https://repositorio. ufba.br/ri/bitstream/ri/14340/1/isabela\%202.pdf>. Acesso em: 2 mar. 2017

QUEIROS, A. A. L.; LIMA, L. P. A institucionalização do trabalho do agente comunitário de saúde. Trabalho, Educação e Saúde, Rio de Janeiro, v. 10, n. 2, p. 257-281, 2012. Disponível em: <http:// www.scielo.br/scielo.php?script=sci_arttext\&pid =S1981-77462012000200005>. Acesso em: 2 mar. 2017.

QUEIROZ, A. C. S.; ALBUQEUERQUE, L. G.; MALIK, A. M. Gestão estratégica de pessoas e inovação: estudos de caso no contexto hospitalar. Revista de Administração, São Paulo, v. 48, n. 4, p. 658-670, dez. 2013. Disponível em: <http://www.scielo.br/pdf/rausp/ v48n4/03.pdf>. Acesso em: 2 mar. 2017.

RIZZOTTO, M. L. F. et al. Força de trabalho e gestão do trabalho em saúde: revelações da Avaliação Externa do Programa Nacional de Melhoria do Acesso e da Qualidade da Atenção Básica no Paraná. Saúde em 
Debate, Rio de Janeiro, v. 38, n. esp., p. 237-251, out. 2014. Disponível em: <http://www.scielo.br/pdf/sdeb/ v38nspe/0103-1104-sdeb-38-spe-0237.pdf>. Acesso em: 2 mar. 2017.

RODRIGUES, P. H. A. et al. Regulação do trabalho médico no Brasil: impactos na Estratégia Saúde da Família. Physis, Rio de Janeiro, v. 23, n. 4, p. 1147-1166, dez. 2013. Disponível em: <http://www.scielo.br/scielo. php?pid=S0103-73312013000400007\&script $=$ sci abstract\&tlng=pt>. Acesso em: 2 mar. 2017.

SANCHO, L. G. et al. Rotatividade na força de trabalho da rede municipal de saúde de Belo Horizonte, Minas Gerais: um estudo de caso. Trabalho, Educação e Saúde, Rio de Janeiro, v. 9, n. 3, p. 431-447, nov. 2011. Disponível em: <http://www.scielo.br/scielo. php?pid=S1981-77462011000300005\&script=sci_abstract>. Acesso em: 2 mar. 2017.

SANCINETTI, T. R. et al. Taxa de absenteísmo da equipe de enfermagem como indicador de gestão de pessoas. Revista da Escola de Enfermagem da USP, São Paulo, v. 45, n. 4, p.1007-1012, ago. 2011. Disponível em: <http://www.scielo.br/pdf/reeusp/v45n4/v45n4a31. pdf>. Acesso em: 2 mar. 2017.

SANT'ANNA, C. F. et al. Comunidade: objeto coletivo do trabalho das enfermeiras da Estratégia Saúde da Família. Acta Paulista de Enfermagem, São Paulo, v. 24, n. 3, p. 341-347, 2011. Disponível em: <http://www.scielo.br/scielo.php?pid=S0103$-21002011000300006 \&$ script $=$ sci_abstract $\&$ tlng $=p t>$. Acesso em: 2 mar. 2017

SCHRAIBER, L. B.; PEDUZZI, M. Tendências e possibilidades da investigação de recursos humanos em saúde no Brasil. Educación Médica y Salud, Washington, DC, n. 27, v. 3, p. 295-313, 1993. Disponível em: <http:// pesquisa.bvsalud.org/cvsp/resource/pt/pah-15206>. Acesso em: 2 mar. 2017.

SEIDL, H. et al. Gestão do trabalho na Atenção Básica em Saúde: uma análise a partir da perspectiva das equipes participantes do PMAQ-AB. Saúde em Debate, Rio de Janeiro, v. 38, n. esp., p. 94-108, out. 2014. Disponível em: <http://www.scielo.br/scielo.
php?pid=S0103-11042014000600094\&script=sci abstract\&tlng=es>. Acesso em: 2 mar. 2017.

SILVA, A. A.; ROTENBERG, L.; FISCHER, F. M. Jornadas de trabalho na enfermagem: entre necessidades individuais e condições de trabalho. Revista de Saúde Pública, São Paulo, v. 45, n. 6, p.1117-1126, dez. 2011. Disponível em: <http:// www.scielo.br/scielo.php?script=sci_arttext\&pid $=$ S0034-89102011000600014 $>$. Acesso em: 2 mar. 2017.

SILVA, K. L. et al. Expansão dos cursos de graduação em enfermagem: dilemas e contradições frente ao mercado de trabalho. Revista da Escola de Enfermagem da USP, São Paulo, v. 47, n. 5, p. 1211-1218, out. 2013. Disponível em: <http://www.scielo.br/scielo. php?pid=S0080-62342013000501211\&script $=$ sci_ arttext\&tlng=pt>. Acesso em: 2 mar. 2017.

SILVA, R. H. A.; MIGUEL, S. S.; TEIXEIRA, L. S. Problematização como método ativo de ensino-aprendizagem: estudantes de farmácia em cenários de prática. Trabalho, Educação e Saúde, Rio de Janeiro, v. 9, n. 1, p. 77-93, jun. 2011. Disponível em: <http:// www.scielo.br/scielo.php?script=sci_arttext\&pid =S1981-77462011000100006>. Acesso em: 2 mar. 2017.

SILVA JUNIOR, S. H. A. et al. Validade e confiabilidade do índice de capacidade para o trabalho (ICT) em trabalhadores de enfermagem. Cadernos de Saúde Pública, Rio de Janeiro, v. 27, n. 6, p. 1077-1087, jun. 2011. Disponível em: <http://www. scielo.br/scielo.php?script=sci_arttext $\&$ pid $=$ S0102-311X2011000600005>. Acesso em: 2 mar. 2017

SILVEIRA, R. P.; PINHEIRO, R. Entendendo a necessidade de médicos no interior da Amazônia - Brasil. Rev. bras. educ. med., v. 38, n. 4, p. 451-459, dez. 2014. Disponível em: <http://www.scielo.br/scielo. php?pid=S0100-55022014000400006\&script $=$ sci abstract\&tlng=pt>. Acesso em: 2 mar. 2017.

TOMASI, A. R. P.; RIZZOTTO, M. L. F. Análise da distribuição e composição profissional dos Núcleos de Apoio à Saúde da Família no Paraná. Saúde debate, v. 37, n. 98, p. 427-436, set. 2013. Disponível em: <http://www.scielo.br/scielo. 
php?pid=S0103-11042013000300006\&script=sci abstract\&tlng=es>. Acesso em: 2 mar. 2017.

TORRES, A. R. et al. Inserção, renda e satisfação profissional de médicos formados pela Unesp. Revista Brasileira de Educação Médica, Rio de Janeiro, v. 36, n. 1, p. 32-40, mar. 2012. Disponível em: <http://www. scielo.br/pdf/rbem/v36nl/a05v36nl.pdf>. Acesso em: 2 mar. 2017.

TRAD, L. A. B.; ROCHA, A. A. R. M. Condições e processo de trabalho no cotidiano do Programa Saúde da Família: coerência com princípios da humanização em saúde. Ciência \&t Saúde Coletiva, Rio de Janeiro, v. 16, n. 3, p. 1969-1980, mar. 2011. Disponível em: <http:// www.scielo.br/scielo.php?script=sci_arttext\&pid $=$ S0100-55022012000100005 $>$. Acesso em: 2 mar. 2017.

VIANNA, C. M. M. et al. Modelos econométricos de estimativa da força de trabalho: uma revisão integrativa da literatura. Physis, Rio de Janeiro, v. 23, n. 3, p. 925-950, set. 2013. Disponível em: <http:// www.scielo.br/scielo.php?script=sci_arttext\&pid =S0103-73312013000300014>. Acesso em: 2 mar. 2017.
VIEIRA, M.; CHINELLI, F. Relação contemporânea entre trabalho, qualificação e reconhecimento: repercussões sobre os trabalhadores técnicos do SUS. Ciência \& Saúde Coletiva, Rio de Janeiro, v. 18, n. 6, p.1 591-1600, jun. 2013. Disponível em: <http://www.scielo.br/scielo.php?pid=S1413$-81232013000600011 \&$ script=sci_abstract\&tlng=es $>$. Acesso em: 2 mar. 2017.

VIEIRA, A. N.; SILVEIRA, L. C.; FRANCO, T. B. A formação clínica e a produção do cuidado em saúde e na enfermagem. Trabalho, Educação e Saúde, Rio de Janeiro, v. 9, n. 1, p. 9-24, jun. 2011. Disponível em: $<$ http://www.scielo.br/scielo.php?script=sci_arttext\&pi $\mathrm{d}=$ S1981-77462011000100002 >. Acesso em: 2 mar. 2017.

Recebido para publicação em abril de 2017

Versão final em julho de 2017

Conflito de interesses: inexistente

Suporte financeiro: não houve 